\title{
Impact of mineral dust on cloud formation in a Saharan outflow region
}

\author{
L. Smoydzin ${ }^{1}$, A. Teller ${ }^{2,5}$, H. Tost ${ }^{3}$, M. Fnais ${ }^{4}$, and J. Lelieveld ${ }^{1,2,4}$ \\ ${ }^{1}$ Max-Planck-Institute for Chemistry, Department of Atmospheric Chemistry, P.O. Box 3060, 55020 Mainz, Germany \\ ${ }^{2}$ The Cyprus Institute, Centre for Energy, Environment and Water Research, Nicosia, Cyprus \\ ${ }^{3}$ Institute for Atmospheric Physics, Johannes-Gutenberg University, Mainz, Germany \\ ${ }^{4}$ King Saud University, Riyadh, Saudi Arabia \\ ${ }^{5}$ Weizmann Institute of Science, Rehovot, Israel \\ Correspondence to: L. Smoydzin (linda.smoydzin@mpic.de)
}

Received: 29 November 2011 - Published in Atmos. Chem. Phys. Discuss.: 8 December 2011

Revised: 9 November 2012 - Accepted: 20 November 2012 - Published: 3 December 2012

\begin{abstract}
We present a numerical modelling study investigating the impact of mineral dust on cloud formation over the Eastern Mediterranean for two case studies: (i) 25 September 2008 and (ii) 28/29 January 2003. In both cases dust plumes crossed the Mediterranean and interacted with clouds forming along frontal systems. For our investigation we used the fully online coupled model WRF-chem.

The results show that increased aerosol concentrations due to the presence of mineral dust can enhance the formation of ice crystals. This leads to slight shifts of the spatial and temporal precipitation patterns compared to scenarios where dust was not considered to act as ice nuclei. However, the total amount of precipitation did not change significantly. The only exception occurred when dust entered into an area of orographic ascent, causing glaciation of the clouds, leading to a local enhancement of rainfall. The impact of dust particles acting as giant cloud condensation nuclei on precipitation formation was found to be small. Based on our simulations the contribution of dust to the $\mathrm{CCN}$ population is potentially significant only for warm phase clouds. Nevertheless, the dust-induced differences in the microphysical structure of the clouds can contribute to a significant radiative forcing, which is important from a climate perspective.
\end{abstract}

\section{Introduction}

Mineral dust particles are important constituents of our atmosphere and climate system influencing the radiative bud- get of the earth directly as well as indirectly by acting as ice nuclei (IN) and thereby impacting microphysical and optical properties of clouds (Sassen, 2002; Mahowald and Kiehl, 2003; DeMott et al., 2003; IPCC, 2007). In addition aged dust which has undergone chemical processing can act as giant cloud condensation nuclei (GCCN) which can enhance rain formation as they efficiently collect moisture and grow at the expense of smaller CCN (e.g. Levin et al., 2005). The impact of dust acting as IN or GCCN on cloud processes can depend on various aspects such as the background $\mathrm{CCN}$ concentration (dust outbreaks in clean or polluted regions), the chemical composition of the atmosphere (impact on aging of dust) as well as meteorological conditions. Findings about the influence of coarse mode particles on cloud processes reported in the literature differ significantly in results and are partly contradictory.

Only few observations exist from which conclusions about the impact of dust on clouds could be drawn. Remote sensing analysis of cloud properties over the Aral Sea reveal that dust particles containing a salt coating lead to larger cloud droplets which can enhance precipitation (Rudich et al., 2002). In contrast Rosenfeld et al. (2001) and Mahowald and Kiehl (2003) concluded that dust is likely to suppress precipitation formation, also over the ocean where abundant hygroscopic salt may be available to coagulate with dust particles. Upon characterisation of the chemical composition of aerosol particles in the Saharan outflow region over the western Atlantic, Twohy et al. (2009) concluded that dust 
particles often nucleate droplets and significantly contribute to cloud formation west of Africa.

Numerous modelling studies were carried out so far to investigate the impact of GCCN on clouds. Though the models often either treat microphysical processes in great detail but are not capable of representing aerosol distributions and the meteorological and chemical conditions realistically, or they accurately simulate atmospheric dynamics but use a bulk microphysics scheme, while in most studies atmospheric chemistry and thus a realistic representation of aerosols is not included. Nevertheless, many studies find that increasing the number of CCN most likely suppresses precipitation, in agreement with Rosenfeld et al. (2001) (e.g. Wurzler et al., 2000; Feingold et al., 1999; Khain et al., 2004; Phillips et al., 2002; Yin et al., 2002). Teller and Levin (2006) distinguished the effect of GCCN on clean clouds and found that the effect was negligibly small. In contrast, in polluted clouds the addition of GCCN can reduce precipitation, delay its initiation and increase cloud lifetime, whereas the addition of IN reduces precipitation, an effect which is apparently larger in clean than in polluted clouds. With a similar approach Solomos et al. (2011) conclude that GCCN have almost no effect on cloud processes and in particular on precipitation formation in marine clouds but have a significant impact on precipitation formation over land. Using a global dust microphysics model Lee et al. (2009) conclude that the size of emitted dust particles can have a significant impact on whether dust increases or decreases the number of $\mathrm{CCN}$.

Upon emission mineral dust particles are commonly considered hydrophobic and must undergo chemical aging to be able act as CCN. Through reaction of calcite at the dust particle surface with acids such as $\mathrm{HNO}_{3}, \mathrm{HCl}$ or by reaction with $\mathrm{SO}_{2}$ to form $\mathrm{H}_{2} \mathrm{SO}_{4}$, dust particles become more hygroscopic and can efficiently attract water and become activated as cloud droplets (e.g. Furutani et al., 2008). Sullivan et al. (2009a) find that the timescale of converting dust into particles with a hygroscopicity or $\kappa$-value (Petters and Kreidenweis, 2007) of at least 0.1 can be between a few minutes up to a few hours depending on gaseous nitric acid concentrations. It was shown in various laboratory studies (Sullivan et al., 2009b) and field campaigns that over continents $\mathrm{HNO}_{3}$ and $\mathrm{SO}_{2}$ mainly contribute to the chemical aging of dust whereas over the ocean $\mathrm{HCl}$ is more important for dust processing (Tobo et al., 2010; Sullivan et al., 2007; Dall'Osto et al., 2010). Apart from the gas phase composition i.e. the reactivity of the atmosphere, the chemical processing also depends on the chemical composition of the dust particles and thus on the source region of the dust (Sullivan et al., 2009a). Even though freshly emitted dust particles are almost insoluble, they can adsorb water and grow to CCN sizes (Sorjamaa and Laaksonen, 2007; Kumar et al., 2009a,b). However, measured growth rates from laboratory experiments show that this process is very slow (Gustafsson et al., 2005). Nevertheless, Karydis et al. (2011) showed that considering adsorp- tion growth of mineral dust can lead to a global annual mean increase of CCN by up to $40 \%$.

In contrast, hydrophobic dust particles are known to act as efficient ice nuclei (e.g. Levin et al., 2005). Though recent laboratory studies raise the question if chemically aged dust particles might actually lose their ability to act as IN (Sullivan et al., 2010b,a). Improved understanding of the chemical surface transformation of dust would help to better quantify the impact of dust on cloud formation as a function of transport from its source region. Several studies show that long range transport of dust can influence the formation of clouds over Central Europe (Chaboureau et al., 2011; Klein et al., 2010; Bangert et al., 2012), the west coast of the United States (e.g. van der Heever et al., 2005) or the tropical Atlantic (Karyampudi and Carlson, 1988; Chiapello et al., 2005; Kallos et al., 2006). Based on long term observations in Germany, Klein et al. (2010) conclude that dust contributes significantly to the IN concentration over Central Europe throughout the year, even in periods without significant Saharan dust intrusions.

It might be crucial to consider the impact of dust as a $\mathrm{CCN}$ in regions which are often affected by dust such as outflow regions of the Sahara. In this study we focus on the Eastern Mediterranean, an area often affected by dust events. We have selected two case studies where cyclonic systems lead to the formation of deep clouds and significant precipitation over coastal areas as well as over the ocean, and where at the same time a dust plume originating in Northern Africa crossed the Mediterranean and strongly influenced aerosol concentrations and potentially clouds and precipitation.

\section{Model setup}

The fully coupled chemistry version of the Weather Research and Forecasting model (WRF-chem) (Grell et al., 2005) version 3.1 was used for this study. The treatment of aerosols and aerosol-cloud interactions in WRF-chem is described in detail by Fast et al. (2006) and Chapman et al. (2009) and only a brief overview of the features most relevant for this study is given below:

Gas phase chemistry is calculated using the CBMZ mechanism (Zaveri and Peters, 1999). Direct and indirect aerosol effects are calculated in the model as described by Chapman et al. (2009). The representation of aerosol activation is based on the parametrisation by Abdul-Razzak et al. (1998) and its implementation into WRF-chem follows the description by Chapman et al. (2009) and references therein. Microphysical processes are calculated using a two moment bulk scheme with five hydrometeor classes (cloud water, rain water, ice, graupel, snow) (Lin et al., 1983) with modifications in order to treat cloud drop numbers prognostically. For nests with horizontal resolutions requiring the usage of a convection parametrisation we use the scheme by Grell and Devenyi (2002). For calculating aerosol thermodynamics and 
Table 1. Overview of simulated scenarios.

\begin{tabular}{ll}
\hline NOdust & No dust emissions from Sahara \\
$\tau_{1}$ & All dust is always available as CCN \\
$\tau_{48}$ & Insoluble dust fraction has half-lifetime of $48 \mathrm{~h}$ \\
NOfeedb & Aerosol-radiation feedbacks switched off \\
\hline
\end{tabular}

microphysics the Module for Simulating Aerosol Interactions and Chemistry (MOSAIC) is used (Zaveri et al., 2008). Aerosols in MOSAIC are composed of sulfate, nitrate, ammonium, chloride, sodium, organic carbon, elemental carbon, water, calcium, carbonate and other inorganics (OIN) which account for mineral dust (Fast et al., 2006; Chapman et al., 2009). We apply MOSAIC with 8 bins in the size range between 0.03 to $10 \mu \mathrm{m}$ which is the same size distribution as has been used in the studies by Chapman et al. (2009) and Fast et al. (2006). The choice of this size distribution implies highly resolved coarse and accumulation modes, which is needed for our case studies as we focus on the impact of dust and sea salt particles on cloud processes.

The wind speed driven emission of dust is calculated online in WRF-chem (based on Shaw et al., 2008) and we only emit dust into the four largest size classes. We assume that dust consists of $97 \%$ "Other INorganics", $1.2 \% \mathrm{Ca}$ and $1.8 \% \mathrm{CO}_{3}$ and the hygroscopicity parameter of freshly emitted dust is set to 0 . Aerosol constituents are assigned to the following hygroscopicity parameters: $\mathrm{SO}_{4}: 0.5, \mathrm{NO}_{3}: 0.5$, Ca: $0.1, \mathrm{CO}_{3}: 0.1, \mathrm{NH}_{4}: 0.5, \mathrm{Cl}: 1.16$, Na: 1.16 , OC: 0.14 , BC: 0 . The hygroscopicity of dust particles increases with the lifetime in the atmosphere due to chemical processing. Since in the current version of WRF-chem/MOSAIC only one type of aerosol is considered and aerosols are internally mixed in each bin, the bulk aerosol hygroscopicity used in the aerosol activation scheme is a mean value over all bulk components. Thus as soon as the dust plume crosses the Mediterranean the aerosol composition changes from almost pure dust in the coarse mode to an approximately equal mass ratio of sea salt (having a high hygroscopicity) and dust (having a low hygroscopicity) quickly leading to a bulk hygroscopicity for coarse mode particles which is high enough to activate particles into cloud droplets. Thus the effect of coating and/or mixing of dust with sea salt is to some extent (indirectly) accounted for in the model. As coating due to other processes is currently not implemented we performed a series of sensitivity studies to consider the impact of different timescales of atmospheric dust processing on droplet activation.

We assume that all freshly emitted dust is considered insoluble $(\kappa=0)$. If fresh dust could indeed partly act as CCN, our results would represent an upper limit. Therefore, we performed several sensitivity simulations in which the insoluble dust fraction decreases exponentially with time after emission, with e-folding lifetimes of the insoluble dust fraction of $1 \mathrm{~s}$ and $48 \mathrm{~h}$ (Table 1). Thus the soluble dust fraction increases with time after emission. To consider the impact of

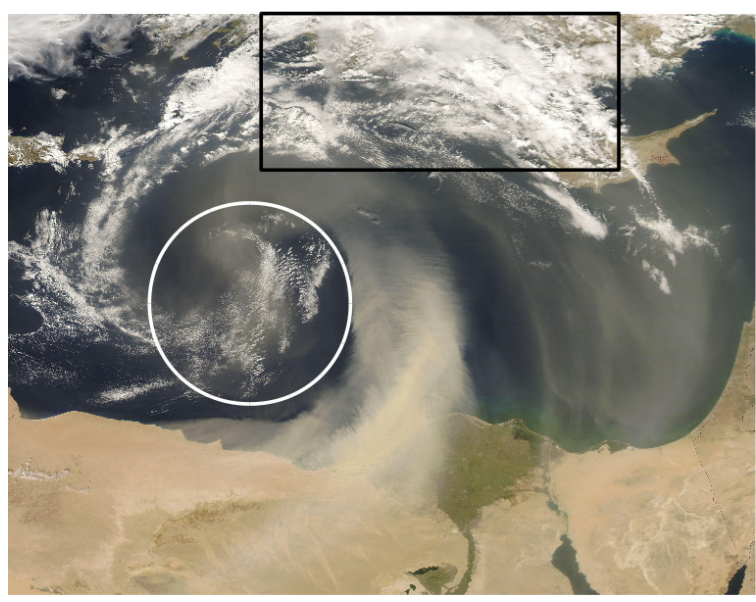

Fig. 1. MODIS visible image, 25 September 2008.

different timescales of dust aging we assume that only the soluble dust fraction is available for activation and thus contributes to the aerosol mass and hygroscopicity.

$N_{\text {insol }}=\left(N \cdot f_{\text {dust }}\right) \exp \left(\frac{-T}{\tau}\right)$
$N=N_{\text {other }}+\left(N_{\text {dust }}-N_{\text {insol }}\right)$

With $N$ being the total number of aerosol particles in each bin, $f_{\text {dust }}$ is the dust (number) fraction (based on the dust mass in each bin), $N_{\text {dust }}$ is the number of dust particles, $N_{\text {other }}$ is the number of particles with a chemical composition other than dust, $T$ is the time since the dust outbreak and $\tau$ is the half-lifetime of the insoluble dust fraction which is varied in the different sensitivity scenarios.

We further performed a sensitivity simulation allowing dust to act as CCN but aerosol-radiation feedbacks were inhibited (scenario NOfeedb).

We have further implemented a parametrisation treating the number of activated ice nuclei diagnostically (DeMott et al., 2010) based on the number of "insoluble" dust particles.

Initial and boundary conditions for gas phase species for our simulations are derived from MATCH-MPIC (Model of Atmospheric Transport and Chemistry, von Kuhlmann et al., 2003) which is ran operationally as a global chemical weather forecasting model at the Max Planck Institute for Chemistry. Initial and boundary conditions for aerosol constituents are taken from simulations performed with the global chemistry-climate model EMAC (Pringle et al., 2010).

The setup of our simulations comprises three nests with horizontal resolutions of $48 \mathrm{~km}, 16 \mathrm{~km}$ and $4 \mathrm{~km}$ and with a vertical resolution of 53 layers with narrow spaced model levels in the lower troposphere and thus at altitudes near the cloud base. 
a)

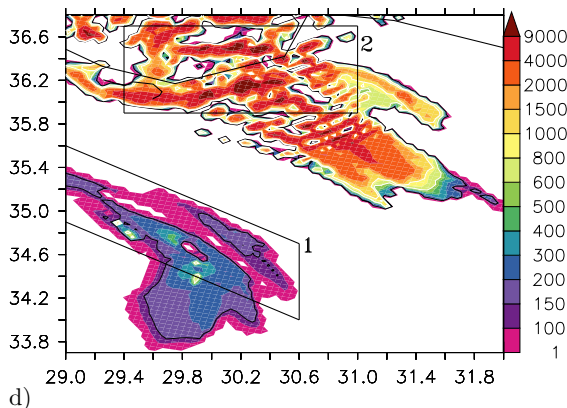

d)

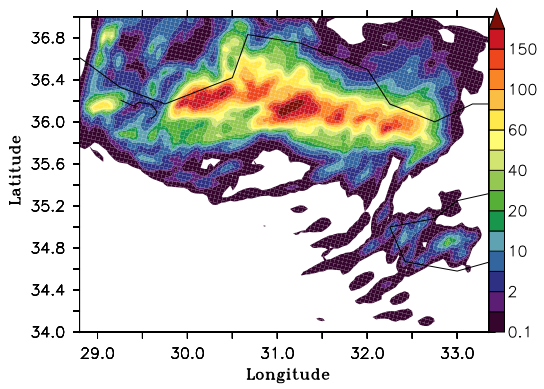

b)

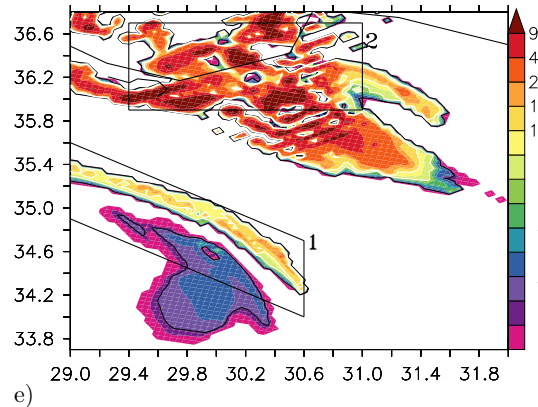

e)

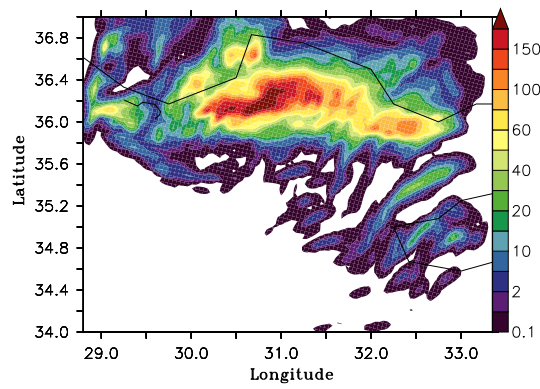

c)

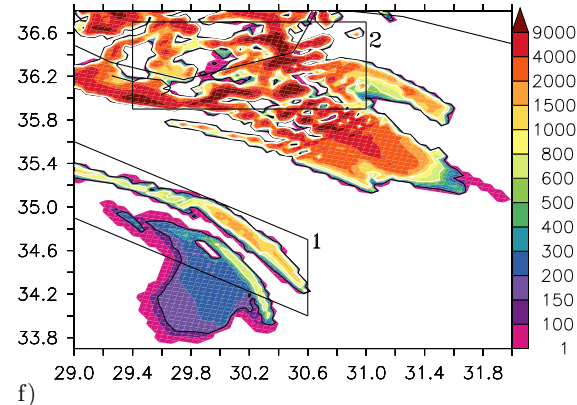

f)

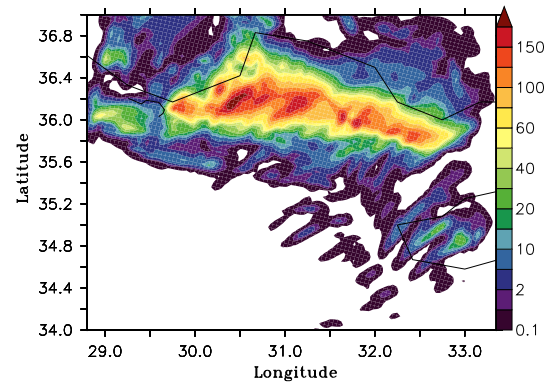

Fig. 2. (a-c) show the column burden of the cloud droplet number concentrations $\left(10^{8} \mathrm{~m}^{-2}\right)$ at 15:00 UTC for the scenarios: (a) NOdust (b) $\tau_{1}$ (c) $\tau_{48}\left(4 \mathrm{~km}\right.$ domain). (d-f) show $24 \mathrm{~h}$ accumulated precipitation (mm) again for scenarios (d) NOdust (e) $\tau_{1}$ (f) $\tau_{48}$.

\section{Case studies - meteorological conditions}

We have selected two case studies representing meteorological conditions being rather typical over the Eastern Mediterranean (Kallos et al., 2007). On all case study days we focus on the intersection region between air masses with a very high dust load and those in which cloud formation took place.

On 25 September 2008 a dust plume crossed the Eastern Mediterranean from South-West to North-East. A low pressure system over the Mediterranean triggered the dust plume in Libya, crossed the island of Cyprus in the evening hours and moved further east towards the Eastern Mediterranean coast. At the same time a cold front lead to cloud formation and precipitation along the coast of the Northern Mediterranean (Greece and Turkey) (Fig. 1).

The second case study was performed for 28 January 2003 when similar meteorological conditions prevailed, however the dust plume only crossed the South-Eastern Mediterranean travelling from Egypt further North to Syria crossing Israel and Lebanon. As the low pressure system passing over the Mediterranean on 28 January 2003 was much more intense than in the autumn case, clouds were significantly deeper and reached altitudes of up to 10 kilometres over extended areas. Again we were interested how the dust plume impacted clouds through aerosol-cloud microphysics and radiative interactions. The meteorological situation prevailing on 28 January 2003 was described in detail by Levin et al. (2005) and Solomos et al. (2011). The simulated dust plume and the cloud band is shown in Fig. 3.

\section{September 2008}

To evaluate the model setup, we compare the simulated aerosol optical thickness (AOD) at 550nm with data derived from the MODIS and MISR satellite instrument. AOD values as well as the location of enhanced AODs seem to agree well between WRF-chem and the satellite data (Fig. 1 in the Supplement). Although an area of enhanced AOD (values around 1) South-East of Crete is not represented in the model simulation. It is possible that the satellite retrieval in this area is influenced by the clouds as the visible image of MODIS (Fig. 1) shows only a thin dust layer there. In addition the simulated dust plume has a slightly less cyclonic structure than apparent in the MODIS image. The comparison of simulated PM10 concentrations with data from the EMEP station at Agia Marina (Cyprus) shows in general good agreement regarding the mass concentration especially during the dust event, though the dust plume crosses Cyprus several hours earlier during the day in the model simulation than observed (Fig. 4 in the Supplement). As the synoptic conditions are simulated realistically this timeshift does not have any impact on our analysis and the exact timing of the dust event would only be important from an operational forecasting point of view. Furthermore, we compared $24 \mathrm{~h}$ accumulated precipitation with observations (Fig. 2 in the Supplement). Unfortunately, the network of rain gauges is not dense enough to extensively evaluate if the regions of maximum precipitation are simulated correctly. Nevertheless, for all available stations, the equivalent simulated precipitation is in general in good agreement. 


\subsection{Impact of dust on cloud processes}

\subsubsection{Warm phase clouds}

In the early afternoon, low level (warm phase) clouds start forming southwest of the dust plume. These clouds can be seen in the MODIS image in their early developing stage (white circle, Fig. 1). In all cases where dust is allowed to act as $\mathrm{CCN}$, particles get activated at the southern edge of the dust plume leading to a slightly, but not significant northward extension of the cloudy area compared to the NOdust scenario (Fig. 2a-c, area (1)). The (arithmetic) mean of the cloud droplet number column burden in this region $\left(29^{\circ}-31^{\circ} \mathrm{E}\right.$, $\left.33.5^{\circ}-35.4^{\circ} \mathrm{N}\right)$ is largest in scenario $\tau_{1}\left(109.1 \times 10^{8} \mathrm{~m}^{-2}\right)$ and lowest in scenario NOdust $\left(49.97 \times 10^{8} \mathrm{~m}^{-2}\right)$ and inbetween in scenario $\tau_{48}\left(95.97 \times 10^{8} \mathrm{~m}^{-2}\right)$. However, at the southeastern edge of the cloud, the number of cloud droplets is largest in scenario $\tau_{48}$ (Fig. 2c) due to enhanced activation of accumulation mode particles compared to the other scenarios in that area. Due to the forced differences in the activation efficiency of coarse mode particles we see, as a secondary effect, also a shift in the size distribution of aerosols (activated as well as non-activated).

In none of the simulated cases precipitation was formed in this region; however, radiative properties of the clouds differ between the scenarios due to the changing optical thickness of the clouds. Overall the top of the atmosphere (TOA) cloud radiative forcing is regionally enhanced if dust and clouds coexist with mean values (15:00 UTC) in the region between $29^{\circ}-31^{\circ} \mathrm{E}$ and $33.5^{\circ}-35.4^{\circ} \mathrm{N}$ of $5.75 \mathrm{~W} \mathrm{~m}^{-2}$ (NOdust), $9.08 \mathrm{~W} \mathrm{~m}^{-2}\left(\tau_{1}\right)$ and $16.57 \mathrm{~W} \mathrm{~m}^{-2}$ $\left(\tau_{48}\right)$. Maximum values for the TOA cloud radiative forcing are $\approx 60 \mathrm{~W} \mathrm{~m}^{-2}$ (NOdust) $\approx 65 \mathrm{~W} \mathrm{~m}^{-2}\left(\tau_{1}\right)$ and values exceeding $100 \mathrm{~W} \mathrm{~m}^{-2}$ in scenario $\tau_{48}$. In scenario $\tau_{1}$ the clouds have the largest spatial coverage; however the clouds are thin leading to small maximum values of cloud radiative forcing at the top of the atmosphere compared to scenario $\tau_{48}$.

\subsubsection{Mixed phase clouds}

Simulated precipitation caused by the cyclone was heaviest along the coast of Turkey and over the Aegean in the late afternoon of 25 September 2008. The region of precipitation formation along the coast of Turkey (black square, Fig. 1, region (2), Fig. 2a-c) is almost identical in all sensitivity cases ( $16 \mathrm{~km}$ as well as $4 \mathrm{~km}$ horizontal resolution). The total amount of precipitation simulated along the Turkish coast does also not differ significantly between the modelled scenarios. The differences in the domain-integral precipitation is less than $5 \%$ between scenario NOdust and scenario $\tau_{1}$ as well as between scenario NOdust and NOfeedb (area 2, marked in Fig. 2a, Fig. 6 in the Supplement). However, a small shift of the rain maximum can be seen with increased precipitation over land by introducing hygroscopic dust. Since we did not perform ensemble simulations it is not possible to determine the level of significance of this shift (Fig. $2 \mathrm{~d}-\mathrm{f}$ ). In addition the rain maximum over the sea is shifted slightly further South in scenarios $\tau_{1}$ and $\tau_{48}$ compared to scenario NOdust (between 15:00 and 18:00 UTC, Fig. 7 in the Supplement) as dust particles have highest concentrations there and subsequently act as additional $\mathrm{CCN}$ and IN. In view of the radiative forcings, which are likely to contribute to some dynamical effects, it may be assumed that the level of significance associated with cloud microphysical effects through $\mathrm{CCN}$ changes is low.

The main effect caused by the dust is the increase of ice and subsequently graupel formation causing increased precipitation. We did not find a significant difference in cloud height between the two scenarios either by including or neglecting dust, though the anvil region of the clouds extents slightly further west if dust is included in the simulation. However, the differences in the spatial extent of the clouds are negligibly small.

\subsubsection{Orographic effects}

In the evening hours a thin cloud band with a north-south orientation develops west of the dust plume (west of Cyprus, Fig. 2d-f). These clouds are mainly warm phase clouds and have a negligibly small ice fraction. Precipitation along the coast of Cyprus is initiated earlier and is more intense if dust is present (scenario $\tau_{1}$ ). Even though the clouds hardly exceed the freezing level, the enhanced activation of ice nuclei by dust leads to efficient formation of graupel which in turn leads to an earlier initiation of precipitation (between 19:0021:00 UTC). In addition the total number of cloud droplets is higher by almost a factor of four in some regions of the cloud band if dust is allowed to act as CCN. The formation of ice is facilitated due to orographic lifting along the Trodoos mountains on Cyprus. Both, over the Mediterranean north of Cyprus and over the island, more precipitation is formed if dust is present. The total amount of precipitation simulated in that region (from $31^{\circ} \mathrm{E}$ to $35^{\circ} \mathrm{E}$ and from $33^{\circ} \mathrm{N}$ to $35.7^{\circ} \mathrm{N}$ ) is about $33 \%$ higher with dust than without dust (comparing scenarios NOdust and $\tau_{1}$ ). The precipitation pattern over land differs as well between scenarios NOdust and $\tau_{1}$ leading to a rain maximum further north of Cyprus in the latter case. (22:00-23:00 UTC). The shift of precipitation patterns can be seen in the $24 \mathrm{~h}$ accumulated precipitation for 25 September (Fig. 2d-f).

However, the overall differences in precipitation are of the same order of magnitude between scenarios NOdust and $\tau_{1}$ as well as between scenarios NOfeedb and $\tau_{1}$. When the calculation of aerosol-radiative feedbacks is switched off, precipitation is still initiated slightly earlier than in scenario NOdust as dust is still allowed to act as CCN and IN. However, in scenario NOfeedb the total amount of precipitation formed over Cyprus is significantly smaller than in scenario $\tau_{1}$ and the spatial distribution of rainfall over Cyprus is most similar to scenario NOdust. 
a)

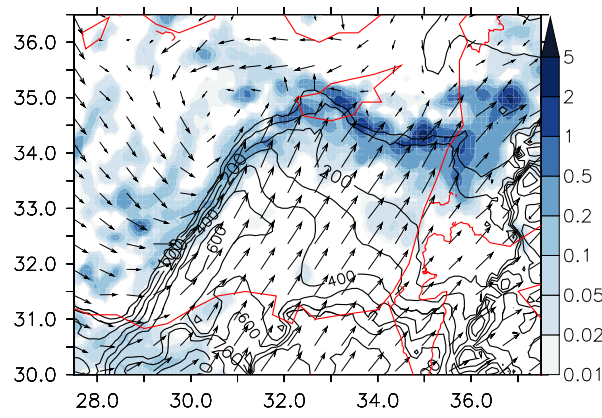

b)

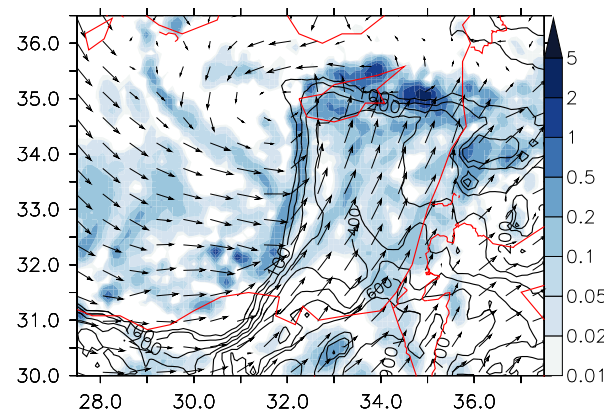

c)

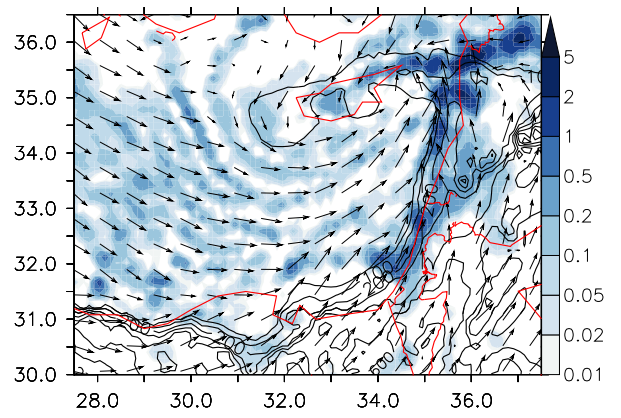

Fig. 3. Column burden of the mixing ratios of integrated total condensate $\left(\mathrm{kg} \mathrm{m}^{-2}\right)$ on 28/29 January 2003 at 12:00 UTC (a), 18:00 UTC (b) and 03:00 UTC (c) for scenario $\tau_{1}$. Contour lines show dust concentrations $\left(\mu \mathrm{g} \mathrm{m}^{-3}\right)$ at $500 \mathrm{~m}$ altitude.

(a)

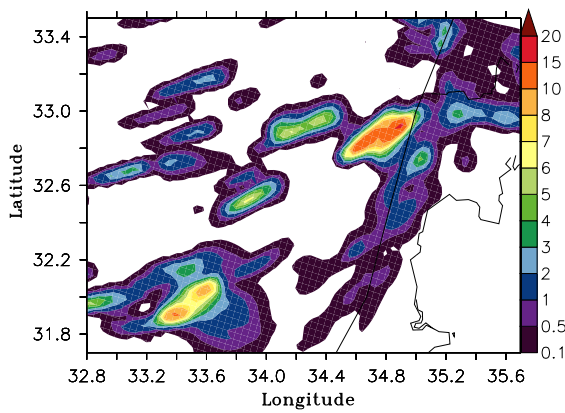

(b)

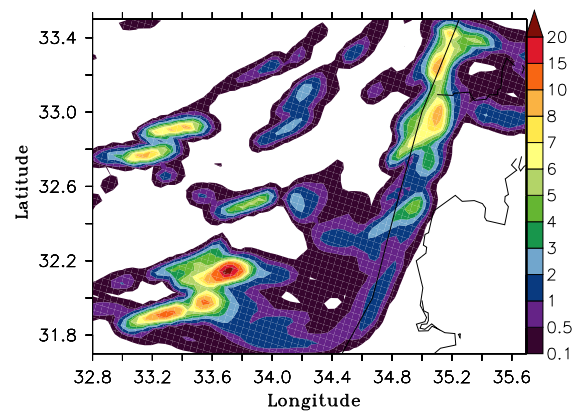

(c)

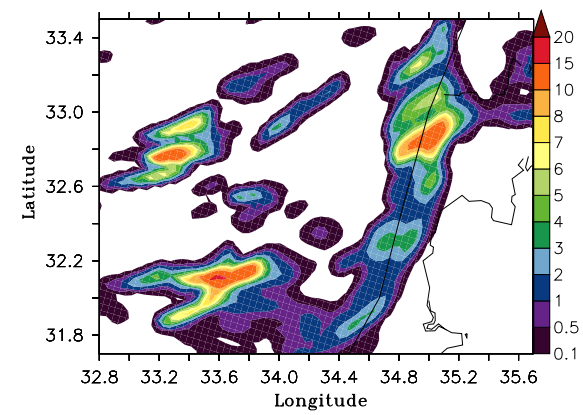

Fig. 4. Simulated accumulated precipitation between 02:00 and 03:00 UTC at 29 January 2003 for the $4 \mathrm{~km}$ domain for the following scenarios: (a) NOdust (b) $\tau_{1}$ (c) $\tau_{48}$.

The coarse mode (aerosol bins $5-8$, with a radius $\geq 1 \mu \mathrm{m}$ ) hygroscopicity in the upper boundary layer and thus in altitudes of cloud base always exceeds a value of 0.1 in our simulations, even in the centre of the dust plume as sodium and chlorine are the dominant coarse mode components (Fig. 5a). Above approximately $1000 \mathrm{~m}$ altitude dust dominates the bulk hygroscopicity within the plume. This further explains why the simulations show largest differences over Cyprus, where the coarse mode hygroscopicity varies between the different model scenarios in altitudes where clouds form.

\section{January 2003}

To further evaluate the model we compare again the simulated AOD with that derived from MODIS. In our model simulation we slightly underestimate the AOD peak values, though the location of the dust plume at 12:00 UTC, 28 January 2003 seems to be realistic. Levin et al. (2005) present observed vertical profiles of aerosol concentrations, showing coarse mode concentrations of 20 to 35 particles per $\mathrm{cm}^{3}$ and accumulation mode concentrations of 800 to 1200 particles per $\mathrm{cm}^{3}$ in the lower troposphere. We have used this data set to evaluate our model setup, and derive aerosol concentrations of the same magnitude. Though coarse mode parti- cle concentrations exceed 100 particles per $\mathrm{cm}^{3}$ in the centre of the dust plume, whereas in the morning of 28 January 2003, simulated accumulation mode particle concentrations are within the lower error range of the observations over the South-Eastern Mediterranean. The spatial extent of the dust plume and aerosol number concentrations also agree with the results presented by Solomos et al. (2011). The $24 \mathrm{~h}$ accumulated precipitation for 28 and 29 January 2003 agrees very well on most locations where rain gauge data was available (Figs. 2, 3 in the Supplement). However, the model most likely overestimates the total amount of precipitation in Cyprus on 28 January and possibly it overestimates the precipitation maximum simulated over North-Western Syria, though again the rain gauge network is not dense enough to evaluate the rainfall maxima in detail. The total amount of rain simulated for the Tel Aviv area is in very good agreement with observations which is crucial as we focus on this area.

In our analysis, we concentrate on two different developing stages of the cyclone and its interactions with the dust plume. 


\subsection{Impact of dust on cloud formation - Northern Mediterranean, 28 January}

Deep convective clouds formed over the North-Eastern Mediterranean in the afternoon of 28 January as can be seen in Fig. 3 (b). The dust plume crossed the Mediterranean from the South-West to North-East and dust-containing air is mixed into the cloud band at its southern edge. This process is very similar to the clouds forming along the Turkish coast for the autumn case. The simulated impact of the dust on cloud processes is also comparable. The dust mixed into the cloud band at its southern edge leads to enhanced ice formation and to higher accretion rates of cloud ice by graupel, which shifts the precipitation maximum further south than in the scenario neglecting dust (Fig. 5 in the Supplement). As more moisture has been removed from the atmosphere further south, less rain is simulated at the northern edge of the cloud band with dust being present. These dust particles acting as GCCN further enhance the probability of freezing and contribute to the increased precipitation rates (in agreement with Teller and Levin, 2006). Thus the total amount of rain formed in that region (between Cyprus and the Syrian coast) hardly differs between the model scenarios including or ignoring dust. The simulated microphysical structure of the cloud remains similar as intensive convection also develops without dust. Even though we can see differences in the precipitation pattern one has to keep in mind that the simulated hourly precipitation is in the range of $15 \mathrm{~mm} \mathrm{~h}^{-1}$ and the difference in hourly precipitation between the NOdust scenario and scenario $\tau_{1}$ is approximately in the range of $5 \mathrm{~mm} \mathrm{~h}^{-1}$.

Similar as for the September-case, significantly more cloud droplets are activated along the western edge of the dust plume. These clouds produce small amounts of rain over the sea and have a relative low ice content. Again, the observed shift in the precipitation maximum along this northsouth oriented cloud band can be attributed to the enhanced ice formation in the presence of dust. However, this difference between the dust and NOdust scenario is very small in that region. Nevertheless, the dust leads to a significant increase in the number of cloud droplets.

\subsection{Impact of dust on cloud formation - Coast, 29 January}

In the model simulations a front-like rain band reaches the coast of the Eastern Mediterranean at approximately 02:00 UTC, 29 January. At that time the dust concentrations still exceed $400 \mu \mathrm{g} \mathrm{m}^{-3}$ at $500 \mathrm{~m}$ altitude along the coast of Israel (Fig. 3c, Supplement Fig. 8c). With dust being present: (i) Precipitation is initiated slightly later along the northern Israel coast (north of $32.8^{\circ} \mathrm{N}$ ) compared to scenario NOdust. However, precipitation along the shoreline between $31.6^{\circ} \mathrm{N}$ and $32.8^{\circ} \mathrm{N}$ is initiated slightly earlier $(\approx 30 \mathrm{~min}$, Fig. 8 in the Supplement); (ii) At the time when precipitation is initiated over land, the cloud extents further south, being more parallel to the coast; (iii) The precipitation maximum is slightly further south; (iv) The precipitation maximum is less intense, but rainfall is more widespread (Fig. 4); (v) The $24 \mathrm{~h}$ accumulated precipitation maximum is further south (closer to Tel Aviv, which is more realistic) but a second precipitation maximum is simulated at the southern coast of Israel (Fig. 2 in the Supplement).

The change of the rain pattern after the cloud reaches the land is a direct effect of dust being activated as $\mathrm{CCN}$ along the coast line, leading to more cloud droplets in addition to ice formation due to orographic lifting and more dust-IN being present. The domain-total-precipitation between all simulated scenarios does however, not differ significantly.

In contrast to the autumn case, the coarse mode bulk hygroscopicity is below a value of 0.1 also in the lowest part of the boundary layer even though dust mixing ratios do not strongly vary between both case studies (Fig. 5b) . However, the dust transport time over the sea is much shorter on 28 January. Thus the time for dust to mix with sea salt is much shorter. In addition, part of the dust along the Israel coast does not pass over the Mediterranean hence cannot mix with sea salt.

\section{Discussion and conclusions}

One significant difference between the case studies presented here, and the more idealised model investigations as mentioned in the introduction ( $2 \mathrm{~d}$ and $3 \mathrm{~d}$ ), is the nonhomogeneous spatial aerosol distribution, notably the dust concentration. In addition we considered radiative feedbacks of aerosol particles and clouds which are often neglected in other modelling studies. We also calculated explicitly the chemical composition i.e. the hygroscopicity of aerosol particles. A weakness of the model set up using a bulk microphysics scheme, is that we cannot explicitly account for dust as GCCN leading to larger cloud droplets which may increase the rate of precipitation formation due to efficient collection/coalescence of smaller droplets, as this is only possible with a prognostic cloud droplet size distribution. Thus in our model setup an increased number of $\mathrm{CCN}$ and cloud droplets leads to the opposite effect. More cloud droplets compete for the same amount of moisture leading to smaller autoconversion rates, thus delaying precipitation formation. A model setup treating the cloud droplet size distribution prognostically would however require the application of a spectral microphysics scheme which is computationally very expensive and has to our knowledge not yet been used in a model in combination with a state of the art aerosol scheme and explicitly calculating chemistry and meteorology online.

In our model setup, we calculate cloud droplet activation following Köhler theory (KT). However, Kumar et al. (2009a) and Kumar et al. (2011) suggest that adsorption activation theory (AT) better represents fresh dust-water interactions than KT. The CCN activity of wet processed dust 
(a)

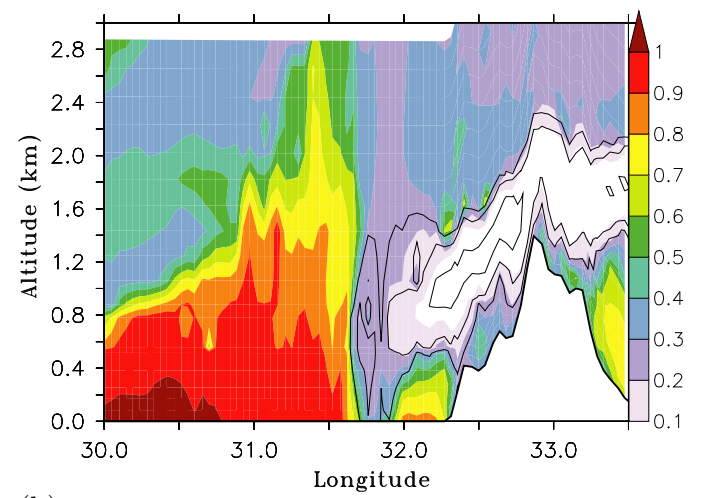

(b)

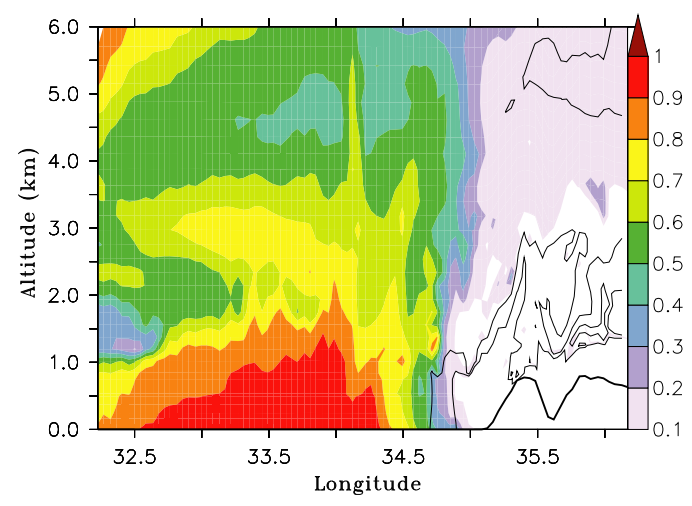

Fig. 5. Coarse mode (aerosol bins 5-8) bulk hygroscopicity at $34.9^{\circ} \mathrm{N}, 20: 00 \mathrm{UTC}, 25$ September 2008 (a) and at $33.3^{\circ} \mathrm{N}$, 2:00 UTC, 29 January 2003 (b) for scenario $\tau_{1}$. Contour lines show dust concentrations $\left(50,100\right.$ and $\left.500 \mu \mathrm{g} \mathrm{m}^{-3}\right)$. The thick black line marks the orography.

though, is more consistent with KT at smaller particle sizes and with AT at larger particle sizes. Therefore, Kumar et al. (2011) developed a unified CCN activity framework (UAF). For internal mixtures it would however, be necessary to know the lagrangian history of each individual aerosol particle to determine its ageing/coating and its hygroscopicity. Strictly, this knowledge would be necessary for deciding whether to apply UAF or KT to calculate the CCN capabilities of the particles. Since this is not feasible in numerical models, mean properties per category (size bin/mode) must be assumed, making it difficult to find an accurate criterion for the application of UAF or KT in models treating aerosols as internal mixtures.

Bangert et al. (2012) use the UAF in one of their sensitivity simulations investigating the impact of dust on cloud formation over central Europe. However, Bangert et al. (2012) assume either that dust particles have no hygroscopic coating during the whole simulation time allowing them to use AT. Or they assume a constant coating of dust particles with $10 \%$ ammonium sulfate justifying the usage of UAF. Instead, the objective of our study is to investigate the impact of a seam- less change in the (dust-) aerosol hygroscopicity upon transport from the source region. In addition, our study focuses on a region close to the dust source. Nevertheless, Bangert et al. (2012) obtain very similar results from their study using slightly different parameterisations and a different model (COSMO-ART) than we do. In both studies, the effect of dust on warm cloud formation is very small.

We investigated the impact of the coarse mode hygroscopicity on aerosol activation. As expected, the largest impact was found for warm phase clouds. Precipitation was not influenced by changing the hygroscopicity, though the number of cloud droplets changed significantly depending on how many particles are available for activation. Furthermore, clouds developed in regions where they did not form if dust was neglected. Both aspects lead to local changes in the TOA cloud radiative forcing. As an indirect effect the difference in cloud cover (depending on how much dust is allowed to be activated) leads to differences in the surface temperature which might affect the dynamical structure and thus the development and lifetime of clouds. However, the maximum difference in below-cloud temperature between scenarios $\tau_{1}$ and $\tau_{48}$ is $\approx 0.04{ }^{\circ} \mathrm{C}$ and $\approx 0.1{ }^{\circ} \mathrm{C}$ between scenarios NOdust and $\tau_{1}$. Temperature differences can be larger in areas where clouds are present only in one scenario $\left(\Delta T_{\max } \approx 0.1-0.5^{\circ} \mathrm{C}\right)$.

Accounting for the chemical aging process of dust and thus its increasing ability to act as a $\mathrm{CCN}$ is mainly important for cloud processes near the source region of the dust. However, recent laboratory results indicate that it might be important to consider the chemical aging of dust more explicitly with respect to its ability to act as IN. If coated dust under certain conditions loses- at least partly - its ability to act as IN it may be crucial to explicitly consider the surface processing of dust also remote from the source region. If this process turns out to be important, the effects of dust on cloud processes over the Mediterranean may become relatively more important whereas they might have been overestimated in regions at greater distance from the dust source such as Europe. In our model setup we assumed that all dust is available as IN. However, under the meteorological conditions occurring during both case studies the dust plume interacts quickly with clouds. Thus we consider it realistic to assume that insoluble dust particles still exist after an aerosol lifetime of about only $12 \mathrm{~h}$ in only moderately polluted regions $\left(\mathrm{HNO}_{3}\right.$ mixing ratios at $500 \mathrm{~m}$ altitude are in the range of $0.1-1 \mathrm{nmol} \mathrm{mol}^{-1}, \mathrm{SO}_{2} \approx 30-70 \mathrm{pmol} \mathrm{mol}^{-1}$ for September and about $0.01-1 \mathrm{nmol} \mathrm{mol}^{-1} \mathrm{HNO}_{3}$ and $\approx 50 \mathrm{pmol} \mathrm{mol}^{-1}$ $\mathrm{SO}_{2}$ for January).

The largest overall effect of the dust was found over Cyprus in the September case: about 33\% more rain is formed in the area with dust being included in the model compared to model results without dust. One may wonder why the effect is so much smaller along the Israel coast where only a shift of precipitation maxima was found but no change in the overall amount of rain. In September, the additional 
dust particles in the atmosphere lead to rapid ice formation, whereas without dust glaciation is much less efficient on that day. These clouds that form west of Cyprus in the evening are boundary layer clouds and only reach up to freezing regions due to orographic lifting. In January, clouds are generally deeper, the atmosphere is colder and ice is formed more efficiently also without the additional ice nuclei. In addition one has to keep in mind that the number concentrations of aerosols in the Aitken and accumulation mode size ranges available as $\mathrm{CCN}$ exceed the number of GCCN by more than an order of magnitude.

Based on our model simulations, we propose to slightly revise the conclusion drawn by Solomos et al. (2011) i.e., that the effect of dust acting as GCCN is mainly important over land. The effect on precipitation is likely to be stronger there (i) because smaller (hygroscopic) particles are generally abundant over continents whereas sea salt is typical over the ocean and (ii) orographic effects can enhance the GCCN effect (Solomos et al., 2011). Though dust can have a significant impact on cloud-radiative properties over the ocean due to differences in the number and size of cloud droplets and on the spatial extent of clouds. The observations by Twohy et al. (2009) support that this effect is significant and needs to be considered for the Eastern Atlantic where, in addition, aerosol concentrations in the accumulation mode size range are typically smaller than over Europe and Asia. The highly efficient coating of dust by acids over polluted regions, e.g. concluded from the analysis of aircraft measurements over China, makes the consideration of dust acting as $\mathrm{CCN}$ also important. The increase in cloud droplets due to activation of dust often leads to widespread but nonprecipitating clouds (Ma et al., 20110). Even though the Mediterranean is an area often affected by dust plumes from northern Africa, the dust particles need to be transported into areas where the meteorological conditions (updraft, moisture) facilitate cloud formation. Wiacek et al. (2010) found that dust emitted from the Gobi or Taklimakan desert is more likely to affect clouds than Saharan dust. These deserts are located at northern latitudes, in a very different climatological region than the Sahara, thus dust is more likely to be transported into areas where clouds form, though the amount of dust mass being emitted from the Sahara is much larger than from the two smaller deserts.

As mentioned above the ideal setup of a numerical model to investigate indirect aerosol effects would be to use a fully online coupled meteorology-chemistry model (such as WRFchem) and use a prognostic cloud-bin-microphysics scheme. Such a setup would however be computationally limiting. For future research we suggest simulations with a similar design as presented here to provide boundary conditions for a model version using a cloud-bin-microphysics scheme, where the competitive effects of the faster growth of large cloud droplets, activated by dust, is contrasted to the competition by more cloud droplets for the same amount of water. We assume that if the first effect is considered, GCCN can lead to precipitation in regions where rain would not fall without dust though it is likely that the amount of rain produced by this effect would be small, and in general the effect can still be considered to be negligible compared to the impact of dust IN on precipitation formation.

\section{Supplementary material related to this article is available online at: http://www.atmos-chem-phys.net/12/ 11383/2012/acp-12-11383-2012-supplement.pdf.}

Acknowledgements. The research leading to these results has received funding from the King Saud University, Riyadh, and the European Research Council under the European Union's Seventh Framework Programme (FP7/2007-2013)/ERC grant agreement no. 226144.

The service charges for this open access publication have been covered by the Max Planck Society.

Edited by: A. Nenes

\section{References}

Abdul-Razzak, H., Ghan, S., and Rivera-Carpio, C.: A parameterization of aerosol activation 1. Single aerosol type, J. Geophys. Res., 103, 6123-6131, 1998.

Bangert, M., Nenes, A., Vogel, B., Vogel, H., Barahona, D., Karydis, V. A., Kumar, P., Kottmeier, C., and Blahak, U.: Saharan dust event impacts on cloud formation and radiation over Western Europe, Atmos. Chem. Phys., 12, 4045-4063, doi:10.5194/acp-124045-2012, 2012.

Chaboureau, J.-P., Richard, E., Pinty, J.-P., Flamant, C., DiGirolamo, P., Kiemle, C., Behrendt, A., Chepfer, H., Chiriaco, M., and Wulfmeyer, V.: Long-range transport of Saharan dust and its radiative impact on precipitation forecasts: a case study during the Convective and Orographically-induced Precipitation Study (COPS), Q. J. Roy. Meteorol. Soc., 137, 236-251, 2011.

Chapman, E. G., Gustafson Jr., W. I., Easter, R. C., Barnard, J. C., Ghan, S. J., Pekour, M. S., and Fast, J. D.: Coupling aerosolcloud-radiative processes in the WRF-Chem model: Investigating the radiative impact of elevated point sources, Atmos. Chem. Phys., 9, 945-964, doi:10.5194/acp-9-945-2009, 2009.

Chiapello, I., Moulin, C., and Prospero, J.: Understanding the longterm variability of African dust transport across the Atlantic as recorded in both Barbados surface concentrations and large-scale Total Ozone Mapping Spectrometer (TOMS) optical thickness, J. Geophys. Res., 110, D18S10, doi:10.1029/2004JD005132, 2005.

Dall'Osto, M., Harrison, R., Highwood, E., O’Dowd, C., Ceburnis, C., Querol, X., and Achterberg, E.: Variation of the mixing state of Saharan dust particles with atmposheric transport, Atmos. Environ., 44, 3135-3146, 2010.

DeMott, P., Sassen, K., Poellot, M., Baumgardner, D., Rogers, D., Brooks, S., Prenni, A., and Kreidenweis, S.: African dust aerosols as atmospheric ice nuclei, Geophys. Res. Lett., 30, 1732, doi:10.1029/2003GL017410, 2003.

DeMott, P., Prenni, A., Liu, X., Kreidenweis, S., Petters, M., Twohy, C., Richardson, M., Eidhammer, T., and Rogers, D.: Predict- 
ing global atmospheric ice nuclei and distributions and their impact on climate, Proc. Natl. Acad. Sci. USA, 107, 11217-11222, doi:10.1073/pnas.0910818107, 2010.

Fast, J., Gustafson Jr, W., Easter, R., Zaveri, R., Barnard, J., Chapman, E., Grell, G., and Peckham, S.: Evolution of ozone, particulates, and aerosol direct radiative forcing in the vicinity of Houston using a fully coupled meteorology-chemistry-aerosol model, J. Geophys. Res., 111, D21305, doi:10.1029/2005JD006721, 2006.

Feingold, G., Cotton, W., Kreideneis, S., and Davis, J.: The Impact of Giant Cloud Condensation Nuclei on Drizzle Formation in Stratocumulus: Implications for Cloud Radiative Properties, J. Atmos. Sci., 56, 4100-4117, 1999.

Furutani, H., Dall'Osto, M., Roberts, G., and Prather, K.: Assessment of the relative importance of atmospheric aging on $\mathrm{CCN}$ activity derived from field observations, Atmos. Environ., 42, 3130-3142, 2008.

Grell, G. and Devenyi, D.: A generalized approach to parameterize convection combining ensemble and data assimilation techiques, Geophys. Res. Lett., 29, 1693, doi:10.1029/2002GL015311, 2002.

Grell, G., Peckham, S., Schmitz, R., McKeen, S., Frost, G., Skamarock, W., and Eder, B.: Fully coupled 'online' chemistry within the WRF model, Atmos. Environ., 39, 6957-6975, 2005.

Gustafsson, R. J., Orlov, A., Badger, C. L., Griffiths, P. T., Cox, R. A., and Lambert, R. M.: A comprehensive evaluation of water uptake on atmospherically relevant mineral surfaces: DRIFT spectroscopy, thermogravimetric analysis and aerosol growth measurements, Atmos. Chem. Phys., 5, 3415-3421, doi:10.5194/acp-5-3415-2005, 2005.

IPCC: Climate Change 2007:The Physical Basis, in : Changes in Atmospheric Constituents and in Radiative Forcing, edited by P. Forster, V. Ramaswamy, R. Artaxo, T. Berntsen, R. Betts, D. Fahey, J. Haywood, J. Lean, D. Lowe, G. Myhre, J. Nganga, R. Prinn, G. Raga, M. Schulz, and R. V. Dorland, Cambridge University Press, Cambridge, UK and New York, NY, USA, 2007.

Kallos, G., Papadopoulos, A., Katsafados, P., and Nickovic, S.: Transatlantic Saharan dust transport: Model simulation and results, J. Geophys. Res., 111, D09204, doi:10.1029/JD006207, 2006.

Kallos, G., Astitha, M., Katsafados, P., and Spyrou, C.: LongRange Transport of Anthropogenically and Naturally Produced Particulate Matter in the Mediterranean and North Atlantik: Current State of Knowledge, J. Appl. Met., 46, 1230-1251, doi:10.1175/JAM2530.1, 2007.

Karyampudi, V. and Carlson, T.: Analysis and numerical simulations of the saharan air layer and its effect on easterly wave disturbances, J. Atmos. Sci., 45, 3102-3136, 1988.

Karydis, V., Kumar, P., Barahona, D., Sokolik, I., and Nenes, A.: On the effect of dust particles on global cloud condensation nuclei and cloud droplet number, J. Geophys. Res., 116, D23204, doi:10.1029/2011jd016283, 2011.

Khain, A., Pokrovsky, A., Pinsky, M., Seifert, A., and Phillips, V.: Simulation of Effects of Atmospheric Aerosols on Deep Turbulent Convectiove Clouds Using a Spectral Microphysics MixedPhase Cumulus Cloud Model. Part 1: Model Description and Possible Application, J. Atmos. Sci., 61, 2963-2982, 2004.
Klein, H., Nickovic, S., Haunold, W., Bundke, U., Nillius, B., Ebert, M., Weinbruch, S., Schuetz, L., Levin, Z., Barrie, L. A., and Bingemer, H.: Saharan dust and ice nuclei over Central Europe, Atmos. Chem. Phys., 10, 10211-10221, doi:10.5194/acp10-10211-2010, 2010.

Kumar, P., Nenes, A., and Sokolik, I.: Importance of adsorption for CCN activity and hygroscopic properties of mineral dust aerosol, Geophys. Res. Lett., 36, L24804, doi:10.1029/2009GL040827, 2009a.

Kumar, P., Sokolik, I. N., and Nenes, A.: Parameterization of cloud droplet formation for global and regional models: including adsorption activation from insoluble CCN, Atmos. Chem. Phys., 9, 2517-2532, doi:10.5194/acp-9-2517-2009, 2009b.

Kumar, P., Sokolik, I. N., and Nenes, A.: Cloud condensation nuclei activity and droplet activation kinetics of wet processed regional dust samples and minerals, Atmos. Chem. Phys., 11, 8661-8676, doi:10.5194/acp-11-8661-2011, 2011.

Lee, Y. H., Chen, K., and Adams, P. J.: Development of a global model of mineral dust aerosol microphysics, Atmos. Chem. Phys., 9, 2441-2458, doi:10.5194/acp-9-2441-2009, 2009.

Levin, Z., Teller, A., Ganor, E., and Yin, Y.: On the interactions of mineral dust, sea-salt particles, and clouds: A measurement and modeling study from the Mediterranean Israeli Dust Experiment campaign, J. Geophys. Res., 110, D20202, doi:10.1029/2005JD005810, 2005.

Lin, Y.-L., Farley, R., and Orville, H.: Bulk Parameterization of the Snow Field in a Cloud Model, J. Climate Appl. Met., 22, 10651092, 1983.

Ma, J., Chen, Y., Wang, W., Yang, P., Liu, H., Yang, S., Hu, Z., and Lelieveld, J.: Strong air pollution causes widespread haze-clouds over China, J. Geophys. Res., 115, D18204, doi:10.1029/2009JD013065, 20110.

Mahowald, N. and Kiehl, L.: Mineral aerosol and cloud interactions, Geophys. Res. Lett., 30, 1475, doi:10.1029/2002GL016762, 2003.

Petters, M. D. and Kreidenweis, S. M.: A single parameter representation of hygroscopic growth and cloud condensation nucleus activity, Atmos. Chem. Phys., 7, 1961-1971, doi:10.5194/acp-71961-2007, 2007.

Phillips, V., Choularton, T., Blyth, A., and Latham, J.: The influence of aerosol concentrations on the glaciation and precipitation of a cumulus cloud, Q. J. Roy. Meteorol. Soc., 128, 951-971, 2002.

Pringle, K. J., Tost, H., Message, S., Steil, B., Giannadaki, D., Nenes, A., Fountoukis, C., Stier, P., Vignati, E., and Lelieveld, J.: Description and evaluation of GMXe: a new aerosol submodel for global simulations (v1), Geosci. Model Dev., 3, 391-412, doi:10.5194/gmd-3-391-2010, 2010.

Rosenfeld, D., Rudich, Y., and Lahav, R.: Desert dust suppressing precipitation: A possible desertification feedback loop, Proc. Natl. Acad. Sci. USA, 98, 5975-5980, 2001.

Rudich, Y., Khersonsky, O., and Rosenfeld, D.: Treating clouds with a grain of salt, Geophys. Res. Lett., 29, 2060, doi:10.1029/2002GL016055, 2002.

Sassen, K.: Indirect climate forcing over the western US from Asian dust storms, Geophys. Res. Lett., 29, 1465, doi:10.1029/2001GL014051, 2002.

Shaw, W., Allwine, K., Fritz, B., Rutz, F., Rishel, J., and Chapman, E.: An elevation of the wind erosion module in DUSTRAN, Atmos. Environ., 42, 1907-1921, 2008. 
Solomos, S., Kallos, G., Kushta, J., Astitha, M., Tremback, C., Nenes, A., and Levin, Z.: An integrated modeling study on the effects of mineral dust and sea salt particles on clouds and precipitation, Atmos. Chem. Phys., 11, 873-892, doi:10.5194/acp11-873-2011, 2011.

Sorjamaa, R. and Laaksonen, A.: The effect of $\mathrm{H} 2 \mathrm{O}$ adsorption on cloud drop activation of insoluble particles: a theoretical framework, Atmos. Chem. Phys., 7, 6175-6180, doi:10.5194/acp-76175-2007, 2007.

Sullivan, R., Guazzotti, S., Sodeman, D., Tang, Y., Carmichael, G., and Prather, K.: Mineral dust is a sink for chlorine in the marine boundary layer, Atmos. Environ., 41, 7166-7179, 2007.

Sullivan, R. C., Moore, M. J. K., Petters, M. D., Kreidenweis, S. M., Roberts, G. C., and Prather, K. A.: Effect of chemical mixing state on the hygroscopicity and cloud nucleation properties of calcium mineral dust particles, Atmos. Chem. Phys., 9, 33033316, doi:10.5194/acp-9-3303-2009, 2009a.

Sullivan, R., Moore, M., Petters, M., Kreidenweis, S., Roberts, G., and Prather, K.: Timesacle for hygroscopic conversion of calcite mineral particles through heterogeneous reaction with nitric acid, Phys. Chem. Chem. Phys., 11, 7826-7837, 2009 b.

Sullivan, R., Minambres, L., DeMott, P., Prenni, A., Carrico, C., Levin, E., and Kreidenweis, S.: Chemical processing does not always impair heterogeneous ice nucleation of mineral dust particles, Geophys. Res. Lett., 37, L24805, doi:10.1029/2010GL045540, 2010a.

Sullivan, R. C., Petters, M. D., DeMott, P. J., Kreidenweis, S. M., Wex, H., Niedermeier, D., Hartmann, S., Clauss, T., Stratmann, F., Reitz, P., Schneider, J., and Sierau, B.: Irreversible loss of ice nucleation active sites in mineral dust particles caused by sulphuric acid condensation, Atmos. Chem. Phys., 10, 1147111487, doi:10.5194/acp-10-11471-2010, 2010b.

Teller, A. and Levin, Z.: The effects of aerosols on precipitation and dimensions of subtropical clouds: a sensitivity study using a numerical cloud model, Atmos. Chem. Phys., 6, 67-80, doi:10.5194/acp-6-67-2006, 2006.
Tobo, Y., Uhang, D., Matsuki, A., and Iwasaka, Y.: Asian dust particles converted into aqueous droplets under remote marine atmospheric conditions, Proc. Natl. Acad. Sci. USA, 107, 1790417910, 2010.

Twohy, C., Kreidenweis, S., Eidhammer, T., e.V. Browell, Heymsfield, A., Bansemer, A., Anderson, B., Chen, G., Ismail, S., DeMott, P., and Heever, S. V. D.: Saharan dust particles nucleate droplets in eastern Atlantic ocean, Geophys. Res. Lett., 36, L01807, doi:10.1029/2008GL035846, 2009.

van der Heever, S., Carrio, G., Cotton, W., DeMott, P., and Prenni, A.: Impacts of nucleating aerosols on Florida convection. Part 1: Mesoscale simulations, J. Atmos. Sci., 63, 1752-1775, 2005.

von Kuhlmann, R., Lawrence, M., Crutzen, P., and Rasch, P.: A model for studies of tropospheric ozone and nonmethane hydrocarbons: Model description and ozone results, J. Geophys. Res., 108, 4294, doi:10.1029/2002JD002893, 2003.

Wiacek, A., Peter, T., and Lohmann, U.: The potential influence of Asian and African mineral dust on ice, mixed-phase and liquid water clouds, Atmos. Chem. Phys., 10, 8649-8667, doi:10.5194/acp-10-8649-2010, 2010.

Wurzler, S., Reisin, T., and Levin, Z.: Modification of mineral dust particles by cloud processing and subsequent effects on drop size distributions, J. Geophys. Res., 105, 4501-4512, 2000.

Yin, Y., Wurzler, S., Levin, Z., and Reisin, T.: Interactions of mineral dust particles and clouds: Effects on precipitation and cloud properties, J. Geophys. Res., 107, 4724, doi:10.1029/2001JD001544, 2002.

Zaveri, R. and Peters, L.: A new lumped structure photochemical mechanism for large-scale applications, J. Geophys. Res., 104, 30387-30415, 1999.

Zaveri, R., Easter, R., Fast, J., and Peters, L.: Model for Simulating Aerosol Interactions and Chemistry (MOSAIC), J. Geophys Res., 113, D13204, doi:10.1029/2007JD008782, 2008. 